\title{
Prevalence and determinants of diabetes mellitus in high altitude: A cross sectional study in mountainous region of Nepal
}

\author{
Kiran Prasad Acharya ${ }^{1}$, Dipankar Prajapati ${ }^{2}$, Kunjang Sherpa ${ }^{3}$, Aarjan Khanal ${ }^{4}$, \\ Pratima Poudel $^{5}$, Anish Hirachan ${ }^{6}$, Amrit Bogati ${ }^{3}$, Chandra Mani Adhikari ${ }^{2}$ \\ ${ }^{1}$ Senior Resident, Department of Cardiology, Shahid Gangalal National Heart Center, Nepal, ${ }^{2}$ Cardiologist, Department \\ of Cardiology, Shahid Gangalal National Heart Center, Nepal, ${ }^{3}$ Registrar of Cardiology, Department of Cardiology, \\ Shahid Gangalal National Heart Center, Nepal, ${ }^{4} P G$ Trainee in Internal Medicine, Department of Internal Medicine, \\ Kathmandu Medical College, Nepal, ${ }^{5}$ Dermatologist, Department of Pediatric Dermatology, Kanti Children's Hospital, \\ Nepal, ${ }^{6}$ Cardiologist, Department of Cardiology, Nepal Mediciti, Nepal
}

Background: There had been many studies depicting variations in the prevalence of diabetes mellitus in Nepal ranging from $1.4 \%$ to $19 \%$. However, the pooled prevalence was found to be $8.4 \%$. There are only few studies done till date in our part of the world to study the actual prevalence and determinants of Type 2 Diabetes Mellitus ( DM-2) in people residing in mountains. Aims and Objectives: This study was conducted with to estimate the prevalence and determinants of diabetes mellitus among the high-altitude populationin Jomsom district of Nepal. Materials and Methods: A cross sectional study was carried out in Jomsom district of Nepal, at an altitude of 2743 meters on $4^{\text {th }}$ and $5^{\text {th }}$ of June, 2017. A detailed history from the participants of their past medical illness including diabetes mellitus and hypertension was taken. In addition, blood sugar level, blood pressure, anthropometric variables like weight, height, BMI, Waist, Hip, Waist/hip ratio were documented after the verbal consent of the participants. Results: A total of 617 local residents of Jomsom were enrolled in the study. The mean age of study population was $44.4 \pm 17.6$ years with female to male ratio being $1.15: 1$ (53.5\% vs $46.5 \%$ male). The prevalence of diabetes mellitus was found to be $5.2 \%$, which was significantly lower than the overall prevalence of diabetes in the Nepalese population which is $8.4 \%$. Male population was found to have higher prevalence of diabetes in our study. Higher BMI and waist/hip ratio were also associated with increased incidence of diabetes mellitus. This study revealed that compared with individuals with a normal BMI, individuals who were overweight or obese were more likely to be diagnosed with DM-2 (OR [95\% Cl]: ranging from 4.33 [0.96-19.46] for overweight adults to 7.76 [1.76-34.13] for adults in Obesity. Conclusion: The overall prevalence of diabetes mellitus is lower among the individuals residing in higher altitude compared to the general population although the other determinants are comparable.

Key words: Diabetes mellitus; BMI; High altitude population; Waist/hip ratio
Access this article online

Website:

http://nepjol.info/index.php/AJMS DOI: 10.3126/ajms.v11i5.29405

E-ISSN: 2091-0576

P-ISSN: 2467-9100

Copyright (c) 2020 Asian Journal of Medical Sciences

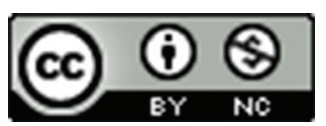

This work is licensed under a Creative Commons Attribution-NonCommercial 4.0 International License.

\section{INTRODUCTION}

Nepal has significant geographic diversity with large area in northern belt covered by mountains. There are human settlements of various ethnic groups in high altitude areas above 3000 meters above sea level. ${ }^{1}$ However, there are very few studies conducted on the prevalence and determinants of diabetes mellitus in the people who reside in high altitude of Nepal.

A total of $6.7 \%$ of Nepalese population reside in mountains whereas globally only about $2 \%$ of the population reside at an altitude of 2500 meters or more. ${ }^{2}$ In the recent decades, diabetes mellitus has been a significant burden to health 
care system throughout the world and its prevalence is increasing in countries of all economic levels.

The actual effect of hypoxic and hypobaric condition in the glucose metabolism is still uncertain. However, there are many hypotheses proposed. Hypoxia results in a preference for glucose utilization and decreases uptake of free fatty acids because of oxygen-deficient adaptation. ${ }^{3} \mathrm{Also}$, the inhibition of gluconeogenesis in hepatocytes in intermittent hypoxia leading to smaller hepatic glucose output can be an important factor for decreased blood glucose profile in inhabitants of high altitude of Nepal. ${ }^{4}$ Moreover, it can also be correlated with the reduced basal insulin level, ${ }^{4}$ increased physical activity and dietary pattern in natives residing in mountains of Nepal.

We aim to study the prevalence of diabetes mellitus andits determinants including various anthropometric measurements and blood pressure in people residing in high altitude region of Nepal.

\section{MATERIALS AND METHODS}

A descriptive cross sectional study was carried out in $4^{\text {th }}$ and $5^{\text {th }}$ June of 2017 at Jomsom of Mustang district of Nepal which is situated at an altitude of 2743 meters from sea level. A routine cardiac screening camp of Shahid Gangalal National Heart Center was conducted and a total of 617 adults of more than 18 years of age were screened.

Adults of either sex, who were the permanent resident at the given place, were enrolled in the study. They were explained about the purpose of study and the methods used. Informed verbal consent was taken assuring full confidentiality. The details of the patients which include sex, age, height, weight, blood pressure, BMI, waist and hip circumference were measured and recorded in a predesigned data collection form.

Fasting Blood Glucose (FBG) and Two-hour postprandial Blood glucose (2-h BG) were measured in 550 adults while only Random blood glucose (RBS) was taken in another 67 adults as they visited in non fasting state. Blood Glucose was measured using capillary blood via glucometer. As it was logistically not possible to measure blood glucose via venous blood in all participants in that set up we used capillary measurement of blood glucose. However, in the initial few participants blood sample was taken for venous blood glucose in addition to capillary blood glucose for cross verification which also revealed that there is not much difference between venous blood and capillary blood glucose level.
Various studies done previously showed strong positive correlation between capillary glucose and venous plasma glucose ${ }^{5}$. Hence capillary glucose measurement can be used as alternative to venous glucose in resource limited situations for screening of diabetes mellitus ${ }^{5}$.

The diagnosis of diabetes was made as per the American diabetes association (ADA) diagnostic criteria for diabetes mellitus, 2015 where adults with FPG $\geq 126 \mathrm{mg} / \mathrm{dl}$ OR 2-h PG $\geq 200 \mathrm{mg} / \mathrm{dL}$ OR the RBS of $\geq 200 \mathrm{mg} / \mathrm{dl}$ with classicsymptoms were diagnosed with diabetes mellitus 6 . In addition, patients already diagnosed with diabetes mellitus and on treatment(oral hypoglycemics and/or insulin) were also included in the study as diabetic population group.

However, it was not feasible to take blood samples for glycated hemoglobin (HBA1c) and performrepeat test of blood glucose profile for final confirmation due to logistic reasons.

Statistical analysis was performed with statistical software (SPSS-22.0 for windows). Results were analyzed using appropriate statistical methods. P-value was calculated under the predetermined level of significance $(0.05)$ and Confidence interval (CI) of $95 \%$ was constructed. Results were expressed in percentage, mean and standard deviation. Ethical clearance was taken from Institutional Review Committee of Shahid Gangalal National Heart Center, Nepal.

\section{RESULTS}

A total of 617 people were screened in the camp, which included 287(46.5\%) male and 330(53.5\%) female. The mean age of the study population was $44.4 \pm 17.6$ years and the mean age of male participants was $44.7 \pm 17.8$ years and the mean age of female was $44.3 \pm 17.5$ years. Various anthropometric measurements are enlisted in Table 1.

There were $32(5.2 \%)$ subjects who were diagnosed with T2DM. Average age of subjects with T2DM was $64.75 \pm 8.7768$ years. The mean age of male subjects with T2DM was $64.7 \pm 9.7$ years and mean age of female subjects with T2DM was $64.8 \pm 6.4$ years.

\begin{tabular}{lcccc}
\multicolumn{3}{c}{ Table 1: Anthropometric measurements $(\mathrm{N}=617)$} \\
\hline & Minimum & Maximum & Mean & $\begin{array}{c}\text { Standard } \\
\text { deviation }\end{array}$ \\
\hline Height $(\mathrm{cm})$ & 108 & 180 & 156.40 & 8.90 \\
Weight $(\mathrm{Kg})$ & 32 & 110 & 62.251 & 11.44 \\
BMI $\left(\mathrm{kg} / \mathrm{m}^{2}\right)$ & 14.23 & 50.59 & 25.46 & 4.28 \\
Waist $(\mathrm{cm})$ & 48 & 130 & 86.73 & 10.58 \\
Hip $(\mathrm{cm})$ & 49 & 166 & 92.71 & 9.47 \\
Waist/hip ratio & 0.47 & 1.63 & 0.93 & 0.07 \\
\hline
\end{tabular}


T2DM was 3.11 times higher in male as compared to female at $95 \% \mathrm{CI}$ ( $\mathrm{p}$ value:0. 003) as shown in Table 2.

T2DM was 14.286 times higher in hypertensive subjects as compared to non-hypertensive at $95 \% \mathrm{CI}$ ( $\mathrm{p}$ value $<0$. 001) as shown in Table 3.

This study revealed that compared with individuals with a normal BMI, individuals who were overweight or obese were more likely to be diagnosed with DM-2 (OR [95\%CI]: ranging from 4.33 [0.96-19.46] for overweight adults to 7.76 [1.76-34.13] for adults in Obesity as shown in Table 4.

Waist/Hip ratio was also significantly high in subjects with T2DM at $95 \%$ CI as shown in Table 5.

Alcohol consumption was present in $29.3 \%$ of the subjects whereas cigarette smoking was present in $15.9 \%$. Likewise, tobacco consumption was present in $8.3 \%$.

\section{DISCUSSION}

Diabetes mellitus is a leading cause of death worldwide with the estimated global prevalence of around 6.4\% and is anticipated to increase up to $7.7 \%$ by $2030 .^{7}$ In Nepal the estimated pooled prevalence of diabetes mellitus is around $8.4 \%$ with the prevalence in urban and rural populations of the country being $8.1 \%$ and $1.0 \%$ respectively. ${ }^{8}$ However, a study done by Sharma et al revealed the overall prevalence of diabetes in Nepalese population to be $6.3 \%$. ${ }^{9}$

There are limited studies regarding the prevalence and determinants of diabetes mellitus in high altitude population in our part of the world. Analysis of the results revealed the overall prevalence of diabetes in inhabitants of high altitude of Nepal to be $5.2 \%$. This is less than the previous 2 studies on overall prevalence of diabetes in Nepalese population. This clearly demonstrates the lower prevalence of diabetes mellitus in the people living in high altitude than in low altitude in Nepal. Although the actual cause of decreased blood sugar profile in inhabitants of high altitude is not clearly understood there are various hypotheses for the same. There are numerous reports suggesting the beneficial effects of living at high altitude on glucose homeostasis. In addition, residents of high altitude also shows better glucose tolerance compared to those living in sea level..$^{10}$ This could probably be due to hypoxia induced decreased gluconeogenesis, reduced hepatic glucose output.

Hypoxia also favors the rate of glycolysis and higher glucose uptake to enter the glycolytic pathway or glucose oxidization to generate the ATP can contribute to lower blood glucose profile in high altitude. Moreover there is important beneficial effect of prolonged hypoxia on insulin sensitivity and decreased prevalence of obesity in high altitude which can be another factor for decreased

\begin{tabular}{|c|c|c|c|c|c|c|}
\hline & & \multicolumn{2}{|c|}{ T2DM } & \multirow[t]{2}{*}{ Total } & \multirow[t]{2}{*}{ OR $(95 \% \mathrm{Cl})$} & \multirow[t]{2}{*}{$p$-value } \\
\hline & & Present & Not present & & & \\
\hline \multirow[t]{2}{*}{ Sex } & Male & 23 & 264 & 287 & $3.11(1.41-6.85)$ & 0.003 \\
\hline & Female & 9 & 321 & 330 & & \\
\hline Total & & 32 & 585 & 617 & & \\
\hline
\end{tabular}

\begin{tabular}{|c|c|c|c|c|c|c|}
\hline & & \multicolumn{2}{|c|}{ T2DM } & \multirow[t]{2}{*}{ Total } & \multirow[t]{2}{*}{ OR $(95 \% \mathrm{Cl})$} & \multirow[t]{2}{*}{$p$-value } \\
\hline & & Present & Not present & & & \\
\hline \multirow[t]{2}{*}{ HTN } & Present & 25 & 117 & 142 & $14.28(6.03-33.83)$ & $<0.001$ \\
\hline & Not Present & 7 & 468 & 475 & & \\
\hline Total & & 32 & 585 & 617 & & \\
\hline
\end{tabular}

Table 4: Association of BMI categories with T2DM

\begin{tabular}{|c|c|c|c|c|c|c|}
\hline & & \multicolumn{2}{|c|}{ T2DM } & \multirow[t]{2}{*}{ Total } & \multirow[t]{2}{*}{ Prevalence of DM (\%) } & \multirow[t]{2}{*}{ Odds ratio (OR) } \\
\hline & & Not present & Present & & & \\
\hline \multirow[t]{3}{*}{ BMI category } & Underweight & 17 & 0 & 17 & & \\
\hline & Overweight & 237 & 13 & 250 & 5.2 & $4.33(P=0.05)$ \\
\hline & Obese & 173 & 17 & 190 & 8.95 & $7.76(P=0.006)$ \\
\hline Total & & 585 & 32 & 617 & & \\
\hline
\end{tabular}


Table 5: Association of Waist/Hip ratio with T2DM

\begin{tabular}{lcccc}
\hline T2DM & Number & $\begin{array}{c}\text { Mean Waist/Hip } \\
\text { ratio }\end{array}$ & $\begin{array}{c}\text { Std. } \\
\text { deviation }\end{array}$ & p-value \\
\hline Not Present & 585 & 0.93 & 0.07 & $<0.001$ \\
Present & 32 & 1.00 & 0.11 & \\
\hline
\end{tabular}

prevalence of diabetes in people living there. ${ }^{11}$ There are other possible mechanisms by which hypoxic environment in highlands may stimulate glucose uptake. One important mechanism is stimulation of glucose uptake by promoting GLUT4 translocation via AMPK-dependent pathway. ${ }^{11}$ Also at the cellular level, hypoxia inhibits oxidative phosphorylation and stimulates oxygen signaling pathway through the hypoxia-inducible factor-1 alpha (HIF-1 alpha). ${ }^{12}$

The result of our study is nearly comparable to the results of the study done in similar geographical region of Nepal by Aryal et al where Overall, 6.9\% of participants residing in high altitude had diabetes or were on hypoglycaemic treatment. ${ }^{3}$ Another study done by Woolcott et al in United States also revealed that diabetes was substantially less prevalent in high-altitude counties compared to low altitude counties $(6.4 \%$ [5.4-7.3] and $9.1 \%[7.8-10.5]) .{ }^{10}$

The study revealed male population had higher prevalence of diabetes mellitus in comparison with the female group (OR 3.11(1.41-6.85), $\mathrm{P}=0.003)$. This finding is similar to the study by Kapil et a ${ }^{13}$ inhigh-altitude region of rural Uttarakhand, India where $14.6 \%$; males $(5.2 \%)$ and females $(9.4 \%)$ were found to have diabetes.

The findings of our study were in contrary to the results obtained from systematic review by Gyawali et al ${ }^{8}$ where female gender were found to have higher prevalence of diabetes in Nepalese general population. Also, in study by Gillett $\mathrm{M}$ et al, ${ }^{14}$ Shera AS et al ${ }^{15}$ and Satman I et al, ${ }^{16}$ positive association of diabetes with female gender was observed.

The odds of having diabetes in hypertensive patient were higher compared to non hypertensive patients OR-14.286 CI (6.032-33.836). The risk factors of both hypertension and diabetes are common and thereby such association could be observed. Similarly, diabetes predisposes to accelerated atherosclerosis, which can result in hypertension on the long run.

T2DM was also significantly associated with increased BMI. The prevalence of diabetes in normal BMI group was $1.25 \%$, in overweight group $5.2 \%$ and in obese group was $8.95 \%$. The people with diabetes had increased waist hip ratio compared to non diabetic population. The mean waist hip ratio in diabetic population was $1.00+/-0.118$, compared to non diabetic group $0.931+/-0.065$. This consolidates the fact that even in high altitude, increased $\mathrm{BMI}$ and waist/hip ratio can be risk factors to develop diabetes mellitus.

\section{CONCLUSION}

The prevalence of diabetes in higher altitude of Nepal was lower compared to the general population. Male sex had higher prevalence of diabetes compared to the female population which was just opposite to that of the national data. BMI and waist hip ratio were also a significant risk factors for diabetes in high altitude. Odds of having diabetes in hypertensive patients were higher than in non hypertensive.

\section{Limitation of the study}

Blood glucose was measured by capillary blood rather than by venous blood as it was logistically not possible although initial few participants blood was taken both for venous blood glucose and capillary blood glucose for cross verification. HbA1c measurement could not be done due to lack of proper logistics.

The prevalence of diabetes in people with the above risk factors was not evaluated. Thus, these may serve as confounding bias in the study. Lipid profile and age group distribution were also not considered in the study.

\section{REFERENCES}

1. Chidi CL. Human Settlements in High Altitude Region Nepal. Geographical Journal of Nepal. 2009;7:1-6. https://doi.org/10.3126/gjn.v7i0.17436

2. Prajapati D, Poudel P, Hirachan A, Sherpa K, Sharma B, Karki D, et al. Prevalence and determinants of Systemic Hypertension in Inhabitants of high altitude of Nepal. Asian Journal of Medical Sciences. 2020;11(3):12-16.

https://doi.org/10.3126/ajms.v11i3.27064

3. Aryal N, Weatherall M, Bhatta YK and Mann S. Lipid profiles, glycated hemoglobin, and diabetes in people living at high altitude in Nepal. International journal of environmental research and public health. 2017;14(9):1041.

https://doi.org/10.3390/ijerph14091041

4. Castillo O, Woolcott OO, Gonzales E, Tello V, Tello L, Villarreal C, et al. Residents at high altitude show a lower glucose profile than sea-level residents throughout 12-hour blood continuous monitoring. High altitude medicine \& biology 2007;8(4):307-311. https://doi.org/10.1089/ham.2007.8407

5. Liu Y, Guo H, Wang Q, Lian D, Yang M, Huang K, et al. Use of capillary glucose combined with other non-laboratory examinations to screen for diabetes and prediabetes. Diabetic Medicine. 2019;36(12):1671-1678.

https://doi.org/10.1111/dme.14101 
6. American Diabetes Association; Diabetes Care 2015 Jan; 38(Supplement 1): S8-S16.https://doi.org/10.2337/dc15-S005 https://doi.org/10.2337/dc15-S005

7. Shaw JE, Sicree RA andZimmet PZ. Global estimates of the prevalence of diabetes for 2010 and 2030. Diabetes Res ClinPract 2010. 87:4-14

https://doi.org/10.1016/j.diabres.2009.10.007

8. Gyawali B, Sharma R, Neupane D, Mishra SR, van Teijlingen E andKallestrup P. Prevalence of type 2 diabetes in Nepal: a systematic review and meta-analysis from 2000 to 2014. Glob Health Action. 2015;8:29088.

https://doi.org/10.3402/gha.v8.29088

9. Sharma SK, Ghimire A, Radhakrishnan J, Thapa L, Shrestha NR, Paudel N, et al. Prevalence of hypertension, obesity, diabetes, and metabolic syndrome in Nepal. International Journal of Hypertension 2011; 19:2011. https://doi.org/10.4061/2011/821971

10. Woolcott OO, Castillo OA, Gutierrez C, Elashoff RM, Stefanovski D and Bergman RN. Inverse association between diabetes and altitude: a cross-sectional study in the adult population of the United States. Obesity (Silver Spring). 2014; 22(9):2080-2090.

https://doi.org/10.1002/oby.20800

11. Woolcott OO, Ader M and Bergman RN. Glucose homeostasis during short-term and prolonged exposure to high altitudes. Endocrine reviews. 2015;36(2):149-173. https://doi.org/10.1210/er.2014-1063

12. Zhang JZ, Behrooz A and Ismail-Beigi F. Regulation of glucose transport by hypoxia. Am J Kidney Dis. 1999;34: 189-202. https://doi.org/10.1016/S0272-6386(99)70131-9

13. Kapil U, Khandelwal R, Ramakrishnan L, Khenduja P, Gupta A, Pandey RM, et al. Prevalence of hypertension, diabetes, and associated risk factors among geriatric population living in a high-altitude region of rural Uttarakhand, India. J Family Med Prim Care. 2018; 7(6):1527-1536.

https://doi.org/10.4103/jfmpc.jfmpc_108_18

14. Gillett M, Royle P, Snaith A, Scotland G, Poobalan A, Imamura $\mathrm{M}$, et al. Non-pharmacological interventions to reduce the risk of diabetes in people with impaired glucose regulation: a systematic review and economic evaluation. Health Technol Assess 2012;16(33):1-236, iii-iv. https://doi.org/10.3310/hta16330

15. Shera AS, Rafique G, Khwaja IA, Baqai S, Khan IA and King H.Pakistan National Diabetes Survey prevalence of glucose intolerance and associated factors in NorthWest at Frontier Province(NWFP) of Pakistan. J Pak Med Assoc 1999; 49: 206-211. https://doi.org/10.1016/S0168-8227(99)00017-0

16. Satman I, Yilmaz T, Sengul A, Salman S, Salman F, Uygur S,et al. Population-based study of diabetes and risk characteristics in Turkey: results of the Turkish diabetes epidemiology study (TURDEP). Diabetes Care 2002; 25: 1551-1556.

https://doi.org/10.2337/diacare.25.9.1551

\section{Authors Contribution:}

KPA - Concept and design of the study, manuscript preparation, statistically analyzed and interpreted, Critical revision of the manuscript; DP - Collected data, statistically analyzed and interpreted, helped in preparing first draft of manuscript; AK - Reviewed the literature, helped in preparing first draft of manuscript; PP - Reviewed the literature, helped in preparing first draft of manuscript; KS - Collected data, statistically analyzed and interpreted, helped in preparing first draft of manuscript; AB - Reviewed the literature, helped in preparing first draft of manuscript; CMA - Concept and design of the study, Reviewed the literature, helped in preparing first draft of manuscript.

\section{Work attributed to:}

Department of Cardiology, Shahid Gangalal National Heart Centre, Kathmandu, Nepal.

Orcid ID:

Dr. Kiran Prasad Acharya - (i) https://orcid.org/0000-0003-2765-4242

Dr. DipankarPrajapati - (1) https://orcid.org/0000-0003-3704-0324

Dr. Kunjang Sherpa - (D) https://orcid.org/0000-0003-1136-6983

Dr. AarjanKhanal - (1) https://orcid.org/0000-0001-5340-0102

Dr. Chandra Mani Adhikari - (1) https://orcid.org/0000-0001-5811-9977

Source of support: None, Conflicts of Interest: None 